\title{
UTILIZAÇÃO DE MÉTODOS ÁGEIS E SUAS IMPLICAÇÕES
}

\author{
Deullam Justi dos Santos ${ }^{1}$ \\ Igor Muzeka ${ }^{2}$ \\ Márcio José Sembay ${ }^{3}$ \\ Juliana Facchini de Souza ${ }^{4}$ \\ Ingrid Solange Sepúlveda Muñoz ${ }^{5}$
}

Resumo: Após a crise de software que ocorreu na década de 70, durante a qual nasceu a engenharia de software, pois os sistemas da época estavam com problemas para serem terminados, estourando prazos e orçamentos, e quando eram terminados tinham uma baixa qualidade com bugs e difícil manutenção. Por conta disso,foram criadas metodologias para o desenvolvimento dos sistemas. Este artigo apresenta 17 métodos ágeis como Scrum, Extreme programing, Lean, que foram utilizados por autores, Foi feita uma pesquisa bibliográfica em artigos onde foi feito uma tabela contendo os autores, metodologias utilizadas e quais os resultados de sua utilização, e gráficos de comparações das metodologias ágeis.

Palavras-chave: Engenharia de software; Métodos ágeis; Scrum; Extreme programing.

\footnotetext{
${ }^{1}$ Ciência da Computação/Centro Universitário Unifacvest, Brasil. E-mail: deullam@yahoo.com.br.

2 Ciência da Computação/Centro Universitário Unifacvest, Brasil. E-mail: igormzk21@gmail.com.

${ }^{3}$ Ciência da Computação/Centro Universitário Unifacvest, Brasil. E-mail: m_sembay@yahoo.com.br.

${ }^{4}$ Ciência da Computação/Centro Universitário Unifacvest, Brasil. E-mail:juacchini1@gmail.com.

${ }^{5}$ Ciência da Computação/Centro Universitário Unifacvest, Brasil. E-mail: professoraingrid2009@hotmail.com.
} 